\title{
Differential regulation of bovine pyruvate carboxylase promoters by fatty acids and peroxisome proliferator-activated receptor- $\alpha$ agonist ${ }^{1}$
}

\author{
H. M. White, S. L. Koser, and S. S. Donkin ${ }^{2}$ \\ Department of Animal Sciences, Interdepartmental Nutrition Program, Purdue University, West Lafayette, IN 47907
}

\section{ABSTRACT}

Pyruvate carboxylase $(\mathrm{PC})$ is a critical enzyme in supplying carbon for gluconeogenesis and oxaloacetate for the tricarboxylic acid cycle. The bovine PC (EC 6.4.1.1) gene contains 3 promoter sequences (P3, P2, and $\mathrm{P} 1$ from $5^{\prime}$ to $\left.3^{\prime}\right)$. Physiological stressors, including the onset of calving and feed restriction, lead to elevated nonesterified fatty acids and glucocorticoid levels that coincide with an increase in PC mRNA expression. The effects of elevated fatty acids on bovine PC mRNA expression and promoter function have not been determined. The objective of this experiment was to determine the direct effects of stearic, oleic, and linoleic acids, dexamethasone, and Wy14643 (a peroxisome proliferator-activated receptor- $\alpha$ agonist) on bovine PC promoter activity. Promoter-luciferase constructs, containing 1,005 bp of P1, 1,079 bp of P2, or 1,010 bp of $\mathrm{P} 3$, were transiently transfected into rat hepatoma (H4IIE) cells. Cells were then treated with $1 \mathrm{~m} M$ stearic, oleic, or linoleic acids, $1 \mu M$ dexamethasone, or $10 \mu M \mathrm{Wy} 14643$ for $23 \mathrm{~h}$. Activity of P1 was suppressed with exposure to stearic acid (1.58 vs. 6.19 \pm 0.81 arbitrary units for stearic vs. control, respectively) and enhanced with exposure to Wy14643 (9.26 vs. $6.19 \pm 0.81$ arbitrary units for Wy14643 vs. control, respectively). Conversely, stearic acid enhanced P3 activity (2.55 vs. $0.40 \pm 0.33$ arbitrary units for stearic vs. control, respectively). Dexamethasone, linoleic acid, and oleic acid failed to elicit a response from any of the promoters tested. These data demonstrate the direct role of fatty acids in regulating $\mathrm{PC}$ expression and indicate that fatty acids provide promoter-specific regulation of $\mathrm{PC}$ promoters.

Key words: pyruvate carboxylase, promoter regulation, peroxisome proliferator-activated receptor- $\alpha$, fatty acids

\footnotetext{
Received October 24, 2010.

Accepted February 14, 2011.

${ }^{1}$ This project was supported by National Research Initiative Competitive Grant no. 2009-35900-05970 from the USDA National Institute of Food and Agriculture.

${ }^{2}$ Corresponding author: sdonkin@purdue.edu
}

\section{INTRODUCTION}

Pyruvate carboxylase (PC; EC 6.4.1.1) activity is critical to the rate of gluconeogenesis from lactate and carbon flux in the tricarboxylic acid cycle. In dairy cows, PC mRNA expression is significantly increased at calving and during feed restriction, whereas other gluconeogenic enzymes such as phosphoenolpyruvate carboxykinase are unchanged (Greenfield et al., 2000; Velez and Donkin, 2005). Increased activity of PC is highly correlated with PC mRNA (Greenfield et al., 2000) and increased capacity of gluconeogenesis from lactate in bovine liver (Velez and Donkin, 2005).

The $5^{\prime}$ untranslated region (UTR) of the bovine mRNA contains 6 variants that are products of 3 promoter $(\mathbf{P})$ regions (P3, P2, and P1 from $5^{\prime}$ to $\left.3^{\prime}\right)$ that produce the same translation product (Hazelton et al., 2008). Although PC mRNA variants originating from P2 and P3 have been observed in all bovine tissues examined, PC mRNA variants from $\mathrm{P} 1$ are only expressed in glucogenic and lipogenic tissues including liver, kidney, and adipose (Agca et al., 2004). Previous work has demonstrated that different physiological or nutritional stressors, such as calving, result in increased UTR variant mRNA expression (Agca and Donkin, 2007).

Elevated NEFA concentrations (Velez and Donkin, 2005) and changes in the profile of fatty acids in plasma and liver (Douglas et al., 2007) occur in response to feed restriction and the transition to lactation, coincident with an increase in PC mRNA expression. This suggests a possible role of fatty acids in the regulation of PC mRNA expression. Previous characterization of plasma fatty acid profiles during the transition period has identified specific fatty acids, including stearic, linoleic, and oleic, that change at parturition (Rukkwamsuk et al., 1999; Douglas et al., 2007). In vitro studies have indicated that many genes are regulated by specific fatty acids and that peroxisome proliferator-activated receptor- $\alpha$ (PPAR $\boldsymbol{\alpha})$ mediates many of these effects (Jump, 2002). In addition to changes in fatty acid profiles at calving, glucocorticoids also change, which may contribute to regulation of gene expression and metabolism (Lanna and Bauman, 1999). 
We hypothesized that bovine PC mRNA expression in liver is regulated by fatty acids, glucocorticoids, and PPAR $\alpha$ agonists. The objective of this experiment was to determine the individual effects of stearic, linoleic, or oleic acids, dexamethasone (dex), or a PPAR $\alpha$ agonist on $\mathrm{PC}$ promoter activities.

\section{MATERIALS AND METHODS}

\section{Promoter Constructs, Hepatoma Cell Culture, and DNA Transfections}

To test the effects of fatty acids on PC promoter activity, cells were transfected separately with promoterluciferase gene constructs containing P1, P2, or P3 of the bovine PC gene linked to a reporter for firefly luciferase. The construct for P1 contained bases 613,522 through 612,518 of bovine chromosome 29 (GenBank accession NW_00149451.1), which corresponds to the region from -1002 through +3 relative to the transcription start site of bovine PC promoter 1 (Hazelton et al., 2008). The P2 construct contained bases 656,939 through 655,865 of bovine chromosome 29 (GenBank accession NW_00149451.1), which corresponds to bases -1074 through +1 relative to the transcription start site for P2. The construct for P3 contained bases 661,335 through 660,330 of bovine chromosome 29 (GenBank accession NW_00149451.1), corresponding to bases -1005 through +1 relative to the transcription start site for P3. Bovine genomic DNA was extracted from liver and used as a template for promoter cloning. Sequences were amplified using PCR and separated by agarose gel electrophoresis and purified using the QIAquick Gel Extraction Kit (Qiagen, Valencia, CA). The purified PCR products (P1, P2, and P3) were ligated separately into the pDrive cloning vector (Qiagen). The cloned sequences were excised from pDrive and ligated individually into the pGL3-basic plasmid (Promega, Madison, WI), which was used to transform competent JM109 Escherichia coli. Selected individual clones were grown overnight, and plasmid DNA was isolated using the Wizard Plus SV Miniprep kit (Promega) and quantified by the absorbance of light at $260 \mathrm{~nm}$ on a NanoDrop 1000 spectrophotometer (NanoDrop Technologies Inc., Wilmington, DE). Correct sequence and orientation of the promoter regions were verified by sequencing at the DNA Sequencing Low Throughput Laboratory of Purdue Genomics Core Facility (Purdue University, West Lafayette, IN) using the ABI 3700 sequencer (Amersham Biosciences, Piscataway, NJ).

For these experiments, plasmids of the pGL3 family (Promega) were used as expression controls. Plasmid pGL3-basic, which lacks a promoter, was used as a negative control for transcription. Two positive pro- moter controls were used: pGL3-promoter, a luciferase reporter plasmid containing the SV40 promoter, and pGL3-control, which contained the SV-40 promoter and an enhancer. Bovine PC promoters 1, 2, and 3 were ligated into pGL3-basic as described above. Cotransfection of cells with a Renilla luciferase plasmid, pRL-CMV (Promega), was used as a normalization control for transfection efficiency.

Rat hepatoma (H4IIE) cells were obtained from the American Type Culture Collection (ATCC, Manassas, VA) and cultured in Dulbecco's modified Eagle's medium (DMEM) containing $4.5 \mathrm{~m} M$ glucose. Cells were plated onto $9.6-\mathrm{cm}^{2}$ wells at a target density of 500,000 cells per well and grown for $24 \mathrm{~h}$ in DMEM supplemented with $10 \%$ fetal bovine serum and $1 \%$ antibiotic-antimycotic solution (Sigma, St. Louis, MO). When cells were $80 \%$ confluent, medium was removed and replaced with $2 \mathrm{~mL}$ of DMEM supplemented with $1 \%$ BSA before transfection.

For cell transfection, a volume of $10 \mu \mathrm{L}$ of Lipofectamine (Invitrogen, Carlsbad, CA) was gently mixed with $240 \mu \mathrm{L}$ of Opti-MEM reduced-serum medium (Invitrogen) and incubated at room temperature for 5 min. A total of $4 \mu \mathrm{g}$ of each plasmid tested and $0.8 \mu \mathrm{g}$ of pRL-CMV were diluted with reduced-serum medium to a total volume of $250 \mu \mathrm{L}$. Diluted plasmids were combined with Lipofectamine (Invitrogen) and incubated at room temperature for $20 \mathrm{~min}$. A volume of 500 $\mu \mathrm{L}$ of the plasmid-Lipofectamine mixture was added to wells prepared as described above and incubated for $5 \mathrm{~h}$ at $37^{\circ} \mathrm{C}$. After initial incubation, medium was refreshed with DMEM containing 1\% BSA (Millipore) and one of the following: (1) stearic acid $(0,125,250,500$, or $1 \mathrm{mM})$; (2) oleic acid (0 or $1 \mathrm{mM})$; or (3) linoleic acid (0 or $1 \mathrm{mM}$ ) bound to BSA (Berry et al., 1991); (4) Wy14643 $(0,0.1$, or $10 \mu M)$; or (5) dex $(0$ or $1 \mu M)$. All treatments were applied to cells containing promoter reporter constructs for $23 \mathrm{~h}$.

\section{Luciferase Activity}

Following incubation for $23 \mathrm{~h}$ with treatments, medium was removed and cells were rinsed with $1 \times$ PBS and harvested in $0.5 \mathrm{~mL}$ of $1 \times$ passive lysis buffer (Promega). Cells were removed to a microcentrifuge tube and frozen to enhance cell lysis. Firefly and Renilla luciferase were quantified in a $20-\mu \mathrm{L}$ volume of cell lysate with the Dual-Luciferase Reporter Assay system and the Stop \& Glo Reagent kit (Promega) according to the manufacturer's instructions. Fluorescence was determined using a Tecan GENios Pro spectrofluorometer with Magellan 5.0 software (Tecan, Research Triangle Park, NC). Data were normalized for transfection efficiency by dividing the relative light units detected 
for firefly luciferase by the corresponding relative light units for Renilla luciferase (firefly:Renilla) for each well. Activity of PC promoters for each treatment was normalized to expression of PGL3-basic. All experiments were repeated in at least 3 separate cell preparations.

\section{Assessment of Cellular Integrity}

To assess the effects of cell manipulation on viability, cells were plated on 96-well plates. Medium was refreshed after $24 \mathrm{~h}$ and cells were incubated for $23 \mathrm{~h}$ at $37^{\circ} \mathrm{C}$ in medium containing stearic, oleic and linoleic acids, dex, or Wy14643 to match incubation conditions for cells used for promoter assessment. The TACS MTT Cell Proliferation Assay (Trevigen, Gaithersburg, MD) was used according to the manufacturer's protocol to determine the effect of treatments on cell viability.

\section{In Silico Promoter Sequence Analysis}

Promoter sequences for bovine PC P1, P2, and P3, described above, were analyzed using the Transcription Element Search System (TESS, University of Pennsylvania; Schug and Overton, 1997). Computer-assisted sequence analysis identified several putative transcription factor response elements on each promoter. Transcription factor site selection was reduced to sequences with a log-likelihood (La) of 12 or greater, a La/length of site score of 2, La/maximum La score for model (L_M) of 1 , and a L_M - La score of 0 .

\section{Statistical Analysis}

Cell culture data were analyzed for normality using the Univariate procedure of SAS 9.2 (SAS Inst. Inc., Cary, NC). Data were analyzed for treatment effect using the Mixed procedure of SAS 9.2 (SAS Inst. Inc.). The model accounted for the fixed effects of treatment and the random effect of cell preparation. Means were considered different when $P<0.05$. Tukey-Kramer studentized adjustments were used to separate treatment means when main effects were significant. When appropriate, orthogonal contrasts were used to evaluate linear and quadratic effects of concentration. Data are reported as least squares means and standard errors.

\section{RESULTS AND DISCUSSION}

The pGL3 luciferase constructs were used as transfection controls in these experiments. The pGL3-promoter construct, containing the SV-40 promoter, permitted expression more $(P<0.05)$ than the promoter-less negative control pGL3-basic. The positive promoter control pGL3-control, which contained the SV-40 promoter and an enhancer, drove luciferase expression more $(P<0.05)$ than either the pGL3-basic or pGL3-promoter constructs (2.60 vs. 0.17 and $0.28 \pm$ 0.19 arbitrary units, pGL3-control vs. pGL3-basic and pGL3-promoter, respectively). Promoter-luciferase constructs for PC P1, P2, and P3 drove expression of luciferase more $(P<0.05)$ than did the negative control pGL3-basic and did not differ $(P \geq 0.1)$ from the positive control pGL3-promoter (Figure 1). The relative order of promoter activity was similar in these data to what has been previously reported (Hazelton et al., 2008). Activities of P1, P2, and P3 were normalized to activity of pGL3-basic for treatment analysis. When the $3 \mathrm{PC}$ promoters were compared, the activity of $\mathrm{P} 1$ was greater $(P>0.05)$ than that of $\mathrm{P} 2$ or $\mathrm{P} 3$ and the activities of P2 and P3 were similar (Figure 1).

Analysis of cellular integrity by TACS MTT Cell Proliferation Assay indicated no difference in cellular

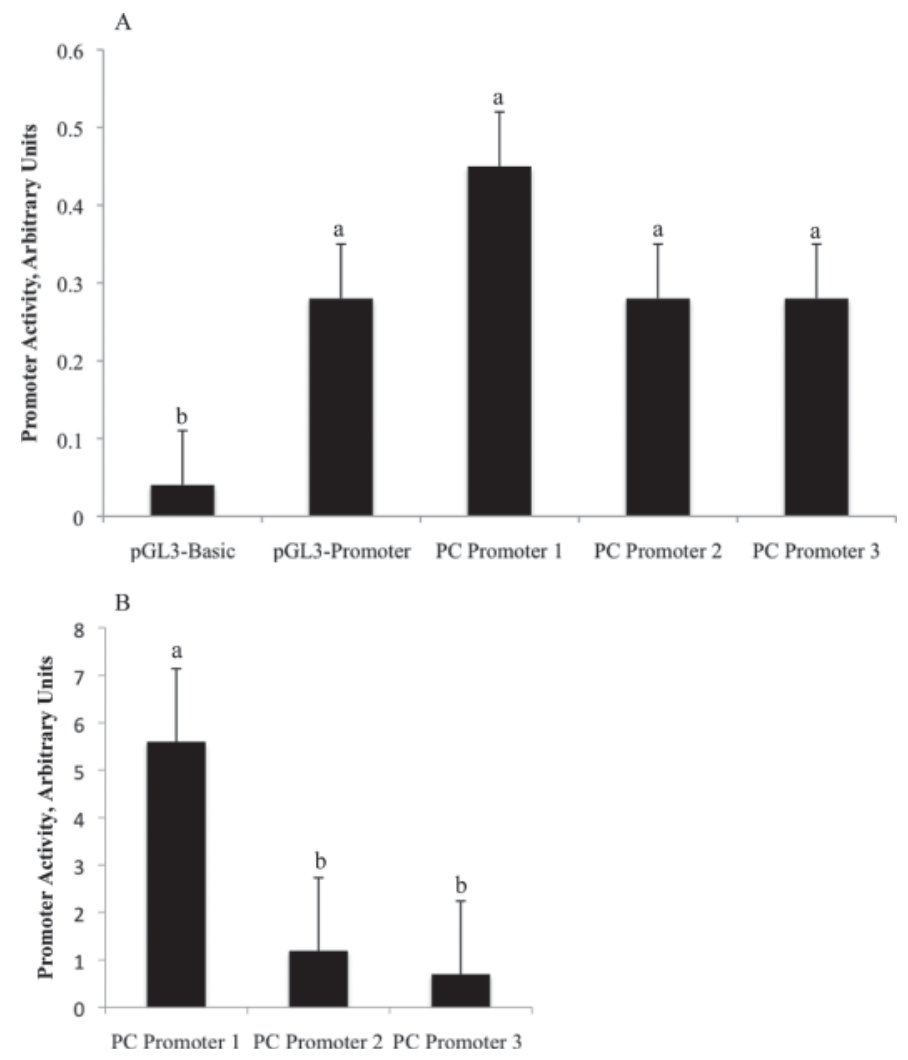

Figure 1. Capacity of bovine pyruvate carboxylase (PC) promoters to drive luciferase expression in H4IIE cells. Cells were transfected with promoter-luciferase gene constructs containing promoter $(\mathrm{P}) 1$, $\mathrm{P} 2$, or P3 of the bovine PC gene linked to firefly luciferase, with the promoter-less plasmid pGL3-basic or with pGL3-promoter (panel A). The plasmids pGL3-basic and pGL3-promoter served as negative and positive promoter expression controls, respectively. Data for relative activities of PC promoters normalized to the expression of pGL3-basic expression (panel B). All promoter activity data were expressed relative to abundance of firefly:Renilla luciferase. Means with different letters are significantly different $(P<0.05)$. 
integrity of cells treated with control or supplemented media (0.68 vs. $0.81 \pm 0.17 \mathrm{~nm}$ for control and treated, respectively). These data indicate a lack of treatment cytotoxicity of the fatty acids, dex, and Wy14643 during the $23 \mathrm{~h}$ of treatment; therefore, the effects of treatments on PC promoters are due to physiological changes rather than differences in cell survivability between the treatments.

\section{Promoter Response to Fatty Acids}

Activities of P1, P2, and P3, assessed through exposure to $1,000 \mu M$ of stearic, oleic, or linoleic acids indicate suppression of P1 with stearic acid (Table 1). Expression of $\mathrm{P} 2$ was not altered $(P \geq 0.05)$ by any treatment compared with control; however, exposure to stearic acid resulted in enhanced $(P<0.05)$ promoter activity compared with cells exposed to either oleic acid or dex. Stearic acid enhanced $(P<0.05)$ P3 expression. The ability of stearic acid to both enhance and suppress the activity of 2 different promoters simultaneously resulted in a promoter by treatment interaction $(P<0.05)$.

Elevated stearic acid concentrations have been noted in plasma of dairy cows around calving (Rukkwamsuk et al., 1999). Concentrations of stearic acid peak at calving whereas concentrations of oleic and linoleic acids remain similar to prepartum levels (Rukkwamsuk et al., 1999; Douglas et al., 2007; Petit et al., 2007). The current data indicate that stearic acid directly regulates bovine PC promoters and suggest that changes in plasma stearic acid concentrations at calving may contribute to changes in the abundance of PC mRNA observed at calving.

Expression of P1 in H4IIE cells decreased $(P<0.05)$ in a linear manner in response to increasing concentrations of stearic acid (Table 2). Cells treated with 250 $\mu M$ of stearic acid had decreased $(P<0.05)$ activity compared with control, and cells exposed to 500 and $1,000 \mu M$ had further decreased $(P<0.05)$ activity. Increasing concentrations of stearic acid resulted in a linear $(P<0.05)$ increase in $\mathrm{P} 2$ promoter activity, although only cells exposed to $1,000 \mu M$ had increased
$(P<0.05)$ activity compared with control cells. Activity of P3 was increased $(P<0.05)$ when cells were exposed to either 500 or $1,000 \mu M$ of stearic acid, although this effect was not linear $(P>0.05)$. In dairy cows, $125 \mu M$ represents the circulating concentration of stearic acid pre- and postcalving, whereas $250 \mu M$ represents the level of circulating stearic acid at calving in healthy cows (Rukkwamsuk et al., 1999). Circulating levels of $500 \mu M$ correspond to circulating stearic acid concentrations at calving in cows with fatty liver (Rukkwamsuk et al., 1999). Total fatty acid concentrations of 1,000 $\mu M$ correspond to total circulating NEFA concentrations in cows with fatty liver at calving (Rukkwamsuk et al., 1999). Promoters 1 and 3 were responsive to stearic acid concentrations less than 1,000 $\mu \mathrm{M}$. The responsiveness to stearic acid concentration may indicate a role for elevated stearic acid concentrations previously observed in transition cows at calving (Rukkwamsuk et al., 1999) to regulate bovine PC expression. The consequence of this effect may be regulation of bovine PC activity during physiological states when gluconeogenesis is upregulated, when hepatic fatty acid supply is increased, or when both conditions exist simultaneously.

Responsiveness of bovine PC P1 to stearic acid was further examined to identify the stearic acid responsive region of the promoter. Cells were transfected with promoter-luciferase constructs containing 1 of 4 segments of $\mathrm{P} 1$ truncated from the $5^{\prime}$ end and then treated with $1,000 \mu M$ stearic acid. Activity of P1 was suppressed $(P<0.05)$ with exposure to stearic acid, regardless of P1 truncation (Figure 2). This indicates that the stearic acid-responsive region is between -222 and +3 bp relative to the transcription start site of P1. Responsiveness of gluconeogenic genes to fatty acids has been examined in rodent models and several fatty acid responsive transcription factors have been identified (Jump and Clarke, 1999; Jump, 2002, 2004; Bauman et al., 2008; Bernard et al., 2009). Key transcription factors involved in gene responsiveness primarily to unsaturated fatty acids include peroxisome proliferatoractivated receptors (PPAR), hepatic nuclear factors, and PPAR $\gamma$-coactivator- $1 \alpha$, which primarily act to

Table 1. Activity of bovine pyruvate carboxylase promoter 1 (P1), promoter 2 (P2), or promoter 3 (P3) after a 23-h exposure to $1 \%$ BSA (control), 1,000 $\mu M$ stearic, linoleic, or oleic acid, $1 \mu M$ dexamethasone (Dex), or $10 \mu M$ Wy14643 (a peroxisome proliferator-activated receptor $\alpha$ agonist)

\begin{tabular}{lcccccccc}
\hline Item $^{1}$ & Control & Stearic & Oleic & Linoleic & Dex & Wy14643 & SEM & $P$-value \\
\hline P1 & $6.19^{\mathrm{b}}$ & $1.58^{\mathrm{c}}$ & $5.58^{\mathrm{b}}$ & $6.31^{\mathrm{ab}}$ & $5.60^{\mathrm{b}}$ & $9.26^{\mathrm{a}}$ & 0.81 & $<0.05$ \\
P2 & $1.09^{\mathrm{ab}}$ & $2.56^{\mathrm{a}}$ & $0.77^{\mathrm{b}}$ & $0.94^{\mathrm{ab}}$ & $0.61^{\mathrm{b}}$ & $1.01^{\mathrm{a}}$ & 0.39 & $<0.05$ \\
P3 & $0.40^{\mathrm{a}}$ & $2.55^{\mathrm{b}}$ & $0.25^{\mathrm{a}}$ & $0.35^{\mathrm{a}}$ & $0.15^{\mathrm{a}}$ & $0.30^{\mathrm{b}}$ & 0.33 & $<0.05$ \\
\hline
\end{tabular}

${ }^{\mathrm{a}-\mathrm{c}}$ Means with different superscripts within promoter are significantly different $(P<0.05)$.

${ }^{1}$ Promoter expression, in arbitrary units, expressed as firefly:Renilla luciferase relative to pGL3-basic expression. 
Table 2. Activity of bovine pyruvate carboxylase promoter 1 (P1), promoter 2 (P2), or promoter 3 (P3) after a 23-h exposure to 0, 125, 250, 500 , or $1,000 \mu M$ stearic acid

\begin{tabular}{lccccccc}
\hline & \multicolumn{5}{c}{ Stearic acid, $\mu M$} & \\
\cline { 2 - 5 } Item $^{1}$ & 0 & 125 & 250 & 500 & 1,000 & SEM & $P$-value \\
\hline P1 & $7.24^{\mathrm{a}}$ & $5.84^{\mathrm{ab}}$ & $4.22^{\mathrm{b}}$ & $0.59^{\mathrm{c}}$ & $1.09^{\mathrm{c}}$ & 0.36 & $<0.05$ \\
P2 & $0.35^{\mathrm{a}}$ & $0.49^{\mathrm{a}}$ & $0.19^{\mathrm{a}}$ & $0.72^{\mathrm{a}}$ & $1.98^{\mathrm{b}}$ & 0.15 & $<0.05$ \\
P3 & $0.14^{\mathrm{a}}$ & $0.49^{\mathrm{a}}$ & $0.20^{\mathrm{a}}$ & $2.75^{\mathrm{c}}$ & $1.33^{\mathrm{b}}$ & 0.31 & $<0.05$ \\
\hline
\end{tabular}

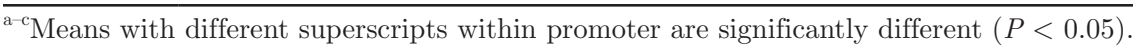

${ }^{1}$ Promoter expression, arbitrary units, expressed as firefly:Renilla luciferase relative to pGL3-basic expression.

upregulate genes coding for key gluconeogenic enzymes (reviewed by Jump et al., 2005; Kalaany and Mangelsdorf, 2006; Sugden et al., 2010). One of the most profound effects of stearic acid to regulate metabolism is an increase in plasma cholesterol, particularly within the low-density lipoprotein (LDL) fraction in blood because of downregulation of the gene for the LDL receptor in liver through modulation of sterol response element binding protein (SREBP)-2 of the LDL receptor promoter (Kan et al., 1999). Likewise, SREBP play a role in repression of microsomal transfer protein and caveolin with implications for cellular cholesterol metabolism and lipoprotein secretion (Shimano, 2001). Although several consensus sequences that modulate the response to stearic acid have been identified (Kan et al., 1999), none of these was present between -222 and +3 of bovine PC P1. Additional experiments are necessary to determine the mechanism of action of stearic acid to repress PC P1 expression and determine if these effects are a direct consequence of novel response element within the bovine PC promoter or an indirect effect of stearic acid on cellular metabolism. Regardless of the mechanism of stearic action on PC P1, the data indicate that the response region is located within 222 bp of the transcription start site.

The effects of stearic acid to activate P3 expression oppose its actions on P1. Incubation with $1 \mathrm{~m} M$ stearic acid activated P3 to 9.5-fold compared with cells incubated with BSA (Table 2). Although considerable evidence links polyunsaturated fatty acids to several transcription factors, including peroxisome proliferator activated receptors, SREBP, and liver X receptor, information on the action of saturated fatty acids to regulate gene expression is limited but their action appears to be linked to SREBP (Vallim and Salter, 2010). Although several putative transcription factor binding sites were identified, none of the factors has been shown to respond directly to stearic acid to promote gene expression.

\section{Promoter Response to PPARa Agonist}

The PPAR $\alpha$ agonist Wy14643 has previously been used in cell culture experiments at concentrations rang-

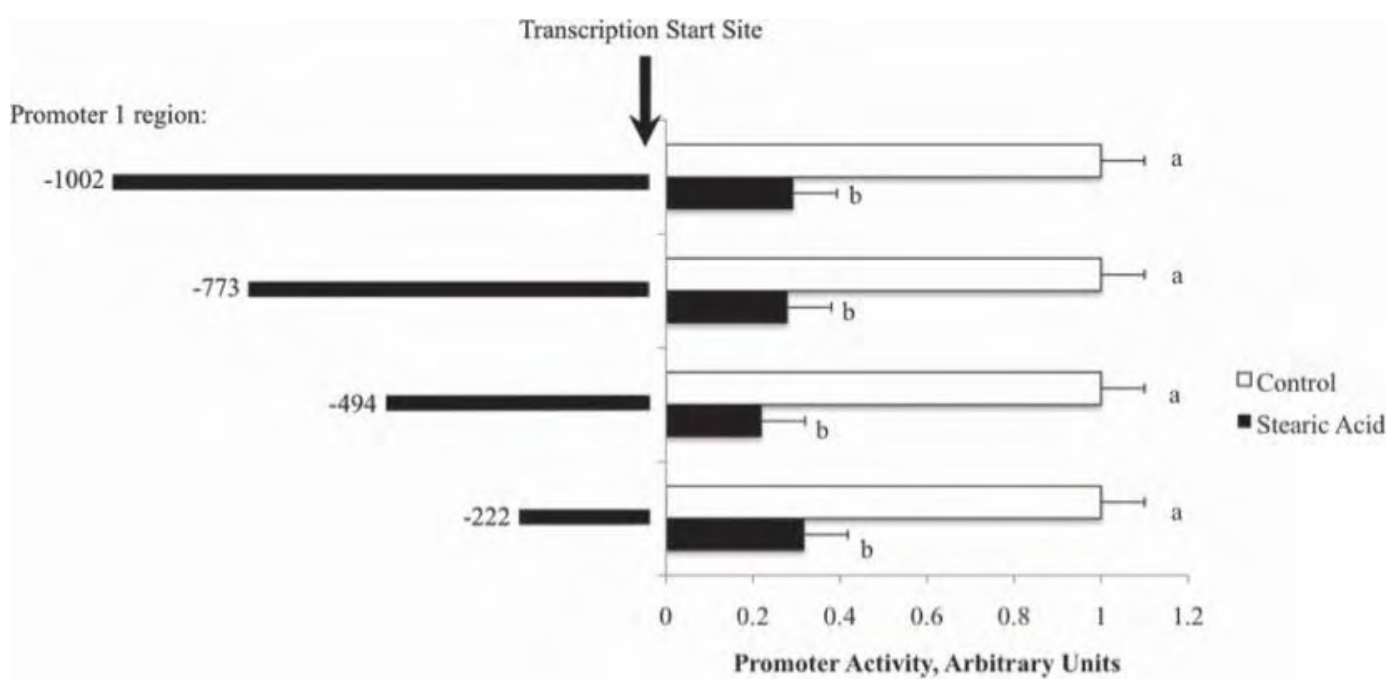

Figure 2. Activity of bovine pyruvate carboxylase promoter 1 regions, serially truncated from the $5^{\prime}$ end, with exposure to stearic acid at 0 (open bars) or $1 \mathrm{mM}$ (solid bars). Means with different letters are significantly different $(P<0.05)$. 
Table 3. Activity of bovine pyruvate carboxylase promoter $1(\mathrm{P} 1)$, promoter $2(\mathrm{P} 2)$, or promoter 3 (P3) after a 23-h exposure to $0,0.1$, or $10 \mu M \mathrm{Wy} 14643$ (a peroxisome proliferator-activated receptor $\alpha$ agonist)

\begin{tabular}{lccccc}
\hline & \multicolumn{3}{c}{ Wy14643, $\mu M$} & & \\
\cline { 2 - 4 } Item $^{1}$ & 0 & 0.1 & & SEM & $P$-value \\
\hline P1 & $7.24^{\mathrm{a}}$ & $8.03^{\mathrm{a}}$ & $9.12^{\mathrm{b}}$ & 0.62 & $<0.05$ \\
P2 & 0.35 & 0.36 & 0.45 & 0.05 & 0.30 \\
P3 & 0.14 & 0.09 & 0.13 & 0.02 & 0.17 \\
\hline
\end{tabular}

${ }^{\mathrm{a}, \mathrm{b}}$ Means with different superscripts within promoter are significantly different $(P<0.05)$.

${ }^{1}$ Promoter expression, arbitrary units, expressed as firefly:Renilla luciferase relative to pGL3-basic expression.

ing from 0.05 to $150 \mu M$ (Koo et al., 2004; Thering et al., 2009). Exposure of cells to 0, 0.1, and $10 \mu M$ Wy14643 indicated that $10 \mu M$ was an effective dose to evoke a PC response in transfected cells (Table 3). Exposure of cells to $0.1 \mu M$ Wy14643 did not alter $(P \geq 0.05) \mathrm{P} 1$ activity; however, exposure to $10 \mu M$ Wy14643 in this experiment increased $(P<0.05) \mathrm{P} 1$ activity. None of the concentrations of Wy14643 tested altered $(P \geq 0.05) \mathrm{P} 2$ or $\mathrm{P} 3$ activity. It is possible that $10 \mu M$ Wy14643 was insufficient to evoke a P2 or P3 response; however, considering the concentrations used in previous experiments, this is not likely.

To identify the PPAR $\alpha$-responsive region of P1, cells were transfected with promoter-luciferase constructs containing 1 of 4 segments of P1 truncated from the 5' end and exposed to $10 \mu M \mathrm{Wy} 14643$. An increase $(P<$ $0.05)$ in promoter activity was observed with cells transfected with -1002 to +3 of P1 treated with Wy14643 and a loss of response $(P<0.05)$ for other $\mathrm{P} 1$ constructs tested (Figure 3). These data indicate that the PPAR $\alpha$ responsiveness for $\mathrm{P} 1$ is within -1002 and -774 of the promoter. Based on sequence analysis, the putative PPARo response element sites for P1 are located between -401 and -74 relative to the transcription start site (Figure 4). Therefore, the effect of Wy14643 to activate $\mathrm{P} 1$ appears to be through a site that is not recognized as a PPAR $\alpha$ binding site by computer analysis, or is through an indirect effect of Wy14643 to activate transcription. Other PPAR $\alpha$-responsive genes possess Sp1 sites that mediate a PPAR $\alpha$ response (Meissner et al., 2004; Yang et al., 2008). For example, activation of vascular endothelial growth factor receptor-2 by PPAR $\alpha$ requires $\mathrm{Sp} 1$ as a co-transcription factor, and mutating this Sp1 site eliminates responsiveness to Wy14643 exposure (Meissner et al., 2004). Identification of Sp1 sites in the -1002 to -774 region of $\mathrm{P} 1$ supports the possibility that Sp1 is involved in PPAR $\alpha$ activation of bovine PC. Additional work is needed to identify the transcription factors specifically involved in the P1 response to PPAR $\alpha$ agonist.

Computer-assisted sequence analysis identified $2 \mathrm{pu}-$ tative PPAR $\alpha$ response elements within P1, 1 for P3,

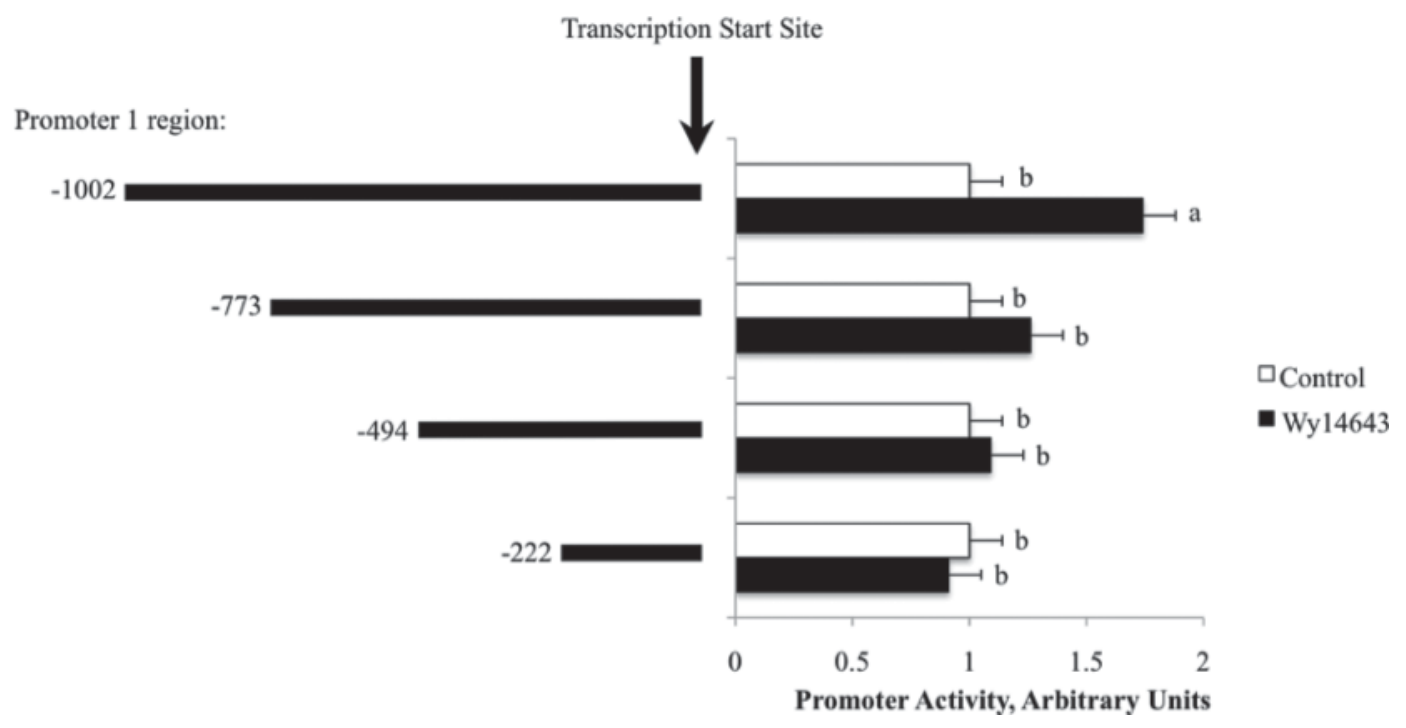

Figure 3. Activity of bovine pyruvate carboxylase promoter 1 regions, serially truncated from the $5^{\prime}$ end, with exposure to Wy14643 (a peroxisome proliferator-activated receptor $\alpha$ agonist) at 0 (open bars) or $10 \mu M$ (solid bars). Means with different letters are significantly different $(P<0.05)$. 


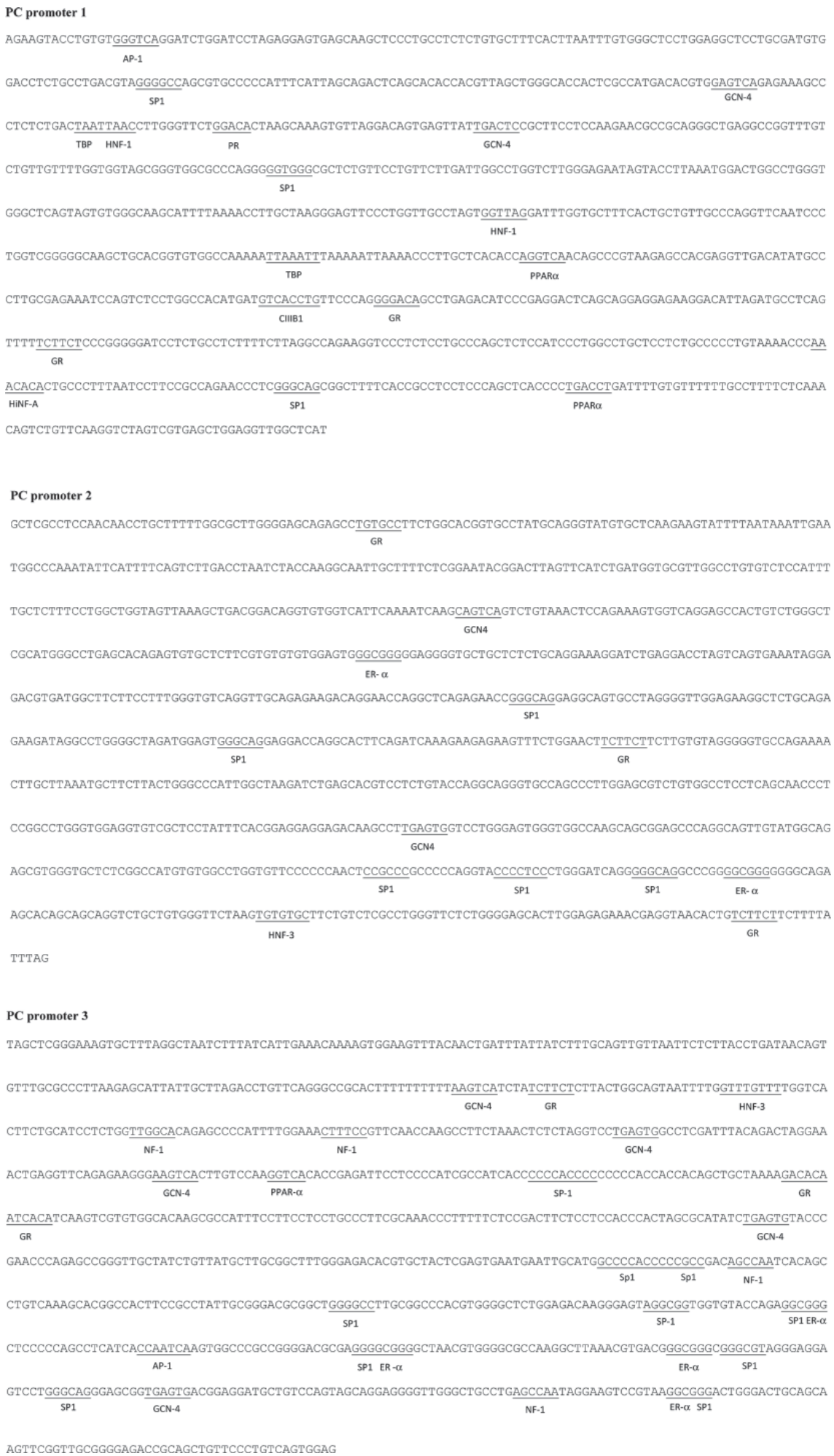

Figure 4. Schematic of putative response elements for bovine pyruvate carboxylase (PC) gene promoter 1 (top), 2 (middle), and 3 (bottom). The region for promoter 1 corresponds to bases -1001 through +3 , promoter 2 to bases -1074 through +1 , and promoter 3 to bases -1005 through +1 , relative to their respective transcription start sites. Putative transcription factor binding sites highlighted were identified using TESS (Schug and Overton, 1997). The sequences represent regions that are responsive to AP-1 (activating protein 1); CIIIB1 (apo-CIII activator 1); ER- $\alpha$ (estrogen receptor $\alpha$ ); GCN-4 (GCN4 leucine zipper); GR (glucocorticoid receptor); HiNF-A (hypoxia inducible factor-A); HNF-1 (hepatic nuclear factor 1); HNF-3 (hepatic nuclear factor 3); NF-1 (nuclear factor 1); PPAR $\alpha$ (peroxisome proliferator-activated receptor $\alpha$ ); PR (progesterone receptor); SP1 (specificity protein 1); TBP (TATA-binding protein). 
and none within P2 (Figure 4). A PPAR $\alpha$ response element has been identified for the rat PC gene (Jitrapakdee et al., 2006) and may mediate the induction of rat $\mathrm{PC}$ promoter 1 expression in response to fatty acids (Jitrapakdee et al., 2006). No response was observed for Wy14643 for bovine PC P2 and P3; however, bovine P1 was activated in response to a PPAR agonist. Similar activation of $\mathrm{PC}$ in vivo may contribute to increased expression of PC mRNA observed at calving (Greenfield et al., 2000) and should be further examined.

\section{Promoter Response to Dexamethasone}

Exposure of cells to dex did not alter $(P \geq 0.1)$ activity of PC P1, P2, or P3 (Table 1). Putative response elements for glucocorticoids located in all 3 bovine PC promoter regions suggested possible promoter responsiveness to dex treatment; however, dex treatment did not affect promoter activity in the current experiments. A modest activation of $\mathrm{P} 2$ by dex has been demonstrated previously using stably transfected cell preparations (Hazelton et al., 2007). A similar response was not evident in the transiently transfected cells used in the current experiments. The reasons for these differences are not clear at present but may be related to differences in dexamethasone concentrations and exposure times. Additional work is necessary to fully exclude glucocorticoids as effectors of PC expression.

Responsiveness of PC to stress and glucocorticoids in vivo is mixed. In rats, dex increased PC activity and gluconeogenesis (Allan and Titheradge, 1984; Jones et al., 1993); however, adrenalectomized rats were able to maintain basal metabolic rates in the absence of glucocorticoids (Martin et al., 1984; Ciprés et al., 1994). In the bovine, glucocorticoid release is elevated at calving and during stress and acts to upregulate lipolysis in adipose tissue (Seitz et al., 1976; Dörr et al., 1989; Lanna and Bauman, 1999). The absence of a direct effect of dex on PC promoter activity in this experiment suggests that any effect of dex to increase bovine PC expression in vivo may be indirect and mediated by changes in circulating fatty acid concentrations.

\section{CONCLUSIONS}

Overall, these data indicate a role for differential regulation of PC by NEFA through either activation or suppression of unique PC promoters. The data demonstrate a specific effect of PPAR $\alpha$ agonist on promoter 1 , and an effect of stearic acid to decrease promoter 1 activity and increase transcription from promoters 2 and 3. Regulation by circulating fatty acids, which are characteristically increased in transition cows, may contribute to increased expression of PC mRNA previously observed at calving. The lack of a dexamethasone effect combined with the differential effects of fatty acids and PPAR $\alpha$ agonist suggest control of PC expression at calving and other physiological states when fatty acid concentrations are elevated.

\section{REFERENCES}

Agca, C., C. A. Bidwell, and S. S. Donkin. 2004. Cloning of bovine pyruvate carboxylase and $5^{\prime}$ untranslated region variants. Anim. Biotechnol. 15:47-66.

Agca, C., and S. S. Donkin. 2007. Expression of pyruvate carboxylase mRNA variants in liver of dairy cattle at calving. PLoS ONE 2:e1270.

Allan, E. H., and M. A. Titheradge. 1984. Effect of treatment of rats with dexamethasone in vivo on gluconeogenesis and metabolite compartmentation in subsequently isolated hepatocytes. Biochem. J. 219:117-123.

Bauman, D. E., J. W. Perfield, K. J. Harvatine, and L. H. Baumgard. 2008. Regulation of fat synthesis by conjugated linoleic acid: Lactation and the ruminant model. J. Nutr. 138:403-409.

Bernard, L., M. Bonnet, C. Leroux, K. J. Shingfield, and Y. Chilliard. 2009. Effect of sunflower-seed oil and linseed oil on tissue lipid metabolism, gene expression, and milk fatty acid secretion in Alpine goats fed maize silage-based diets. J. Dairy Sci. 92:6083-6094.

Berry, M. N., A. M. Edwards, and G. J. Barritt. 1991. Biochemical properties. Pages 121-178 in Laboratory Techniques in Biochemistry and Molecular Biology. Isolated Hepatocytes Preparation, Properties and Applications. Vol. 21. R. H. Burdon and P. H. van Knippenberg, ed. Elsevier, Amsterdam, the Netherlands.

Ciprés, G., E. Urcelay, N. Butta, M. S. Ayuso, R. Parrilla, and A. Martin-Requero. 1994. Loss of fatty acid control of gluconeogenesis and PDH complex flux in adrenalectomized rats. Am. J. Physiol. 267:E528-E536.

Dörr, H. G., A. Heller, H. T. Versmold, W. G. Sippell, M. Herrmann, F. Bidlingmaier, and D. Knorr. 1989. Longitudinal study of progestins, mineralocorticoids, and glucocorticoids throughout human pregnancy. J. Clin. Endocrinol. Metab. 68:863-868.

Douglas, G. N., J. Rehage, A. D. Beaulieu, A. O. Bahaa, and J. K. Drackley. 2007. Prepartum nutrition alters fatty acid composition in plasma, adipose tissue, and liver lipids of periparturient dairy cows. J. Dairy Sci. 90:2941-2959.

Greenfield, R. B., M. J. Cecava, and S. S. Donkin. 2000. Changes in mRNA expression for gluconeogenic enzymes in liver of dairy cattle during the transition to lactation. J. Dairy Sci. 83:1228-1236.

Hazelton, S. R., D. M. Spurlock, C. A. Bidwell, and S. S. Donkin. 2008. Cloning the genomic sequence and identification of promoter regions of bovine pyruvate carboxylase. J. Dairy Sci. 91:91-99.

Hazelton, S. R., D. M. Spurlock, C. A. Bidwell, S. L. Koser, and S. S. Donkin. 2007. Cloning and glucocorticoid responsiveness of bovine pyruvate carboxylase promoters. FASEB J. 21:855.4. (Abstr.)

Jitrapakdee, S., A. Vidal-Puig, and J. C. Wallace. 2006. Anaplerotic roles of pyruvate carboxylase in mammalian tissues. Cell. Mol. Life Sci. 63:843-854.

Jones, C. G., S. K. Hothi, and M. A. Titheradge. 1993. Effect of dexamethasone on gluconeogenesis, pyruvate kinase, pyruvate carboxylase and pyruvate dehydrogenase flux in isolated hepatocytes. Biochem. J. 289:821-828.

Jump, D. B. 2002. Dietary polyunsaturated fatty acids and regulation of gene transcription. Curr. Opin. Lipidol. 13:155-164.

Jump, D. B. 2004. Fatty acid regulation of gene transcription. Crit. Rev. Clin. Lab. Sci. 41:41-78.

Jump, D. B., D. Botolin, Y. Wang, J. Xu, B. Christian, and O. Demeure. 2005. Fatty acid regulation of hepatic gene transcription. J. Nutr. 135:2503-2506.

Jump, D. B., and S. D. Clarke. 1999. Regulation of gene expression by dietary fat. Annu. Rev. Nutr. 19:63-90.

Kalaany, N. Y., and D. J. Mangelsdorf. 2006. LXRS and FXR: The yin and yang of cholesterol and fat metabolism. Annu. Rev. Physiol. 68:159-191. 
Kan, H. Y., P. Pissios, J. Chambaz, and V. I. Zannis. 1999. DNA binding specificity and transactivation properties of SREBP-2 bound to multiple sites on the human apoA-II promoter. Nucleic Acids Res. 27:1104-1117.

Koo, S. H., H. Satoh, S. Herzig, C. H. Lee, S. Hedrick, R. Kulkarni, R. M. Evans, J. Olefsky, and M. Montminy. 2004. PGC-1 promotes insulin resistance in liver through PPAR-alpha-dependent induction of TRB-3. Nat. Med. 10:530-534.

Lanna, D. P., and D. E. Bauman. 1999. Effect of somatotropin, insulin, and glucocorticoid on lipolysis in chronic cultures of adipose tissue from lactating cows. J. Dairy Sci. 82:60-68.

Martin, A. D., E. H. Allan, and M. A. Titheradge. 1984. The stimulation of mitochondrial pyruvate carboxylation after dexamethasone treatment of rats. Biochem. J. 219:107-115.

Meissner, M., M. Stein, C. Urbich, K. Reisinger, G. Suske, B. Staels, R. Kaufmann, and J. Gille. 2004. PPAR $\alpha$ activators inhibit vascular endothelial growth factor receptor-2 expression by repressing Sp1-dependent DNA binding and transactivation. Circ. Res. 94:324-332.

Petit, H. V., M. F. Palin, and L. Doepel. 2007. Hepatic lipid metabolism in transition dairy cows fed flaxseed. J. Dairy Sci. 90:47804792.

Rukkwamsuk, T., T. A. Kruip, G. A. Meijer, and T. Wensing. 1999 Hepatic fatty acid composition in periparturient dairy cows with fatty liver induced by intake of a high energy diet in the dry period. J. Dairy Sci. 82:280-287.

Schug, J., and G. C. Overton. 1997. TESS: Transcription element search software on the WWW. Tech. Report GBIL-TR-1997- 1001-v0.0. Computational Biology and Informatics School of Medicine, University of Pennsylvania, Philadelphia.

Seitz, H. J., M. Kaiser, W. Krone, and W. Tarnowski. 1976. Physiologic significance of glucocorticoids and insulin in the regulation of hepatic gluconeogenesis during starvation in rats. Metabolism $25: 1545-1555$.

Shimano, H. 2001. Sterol regulatory element-binding proteins (SREBPs): Transcriptional regulators of lipid synthetic genes. Prog. Lipid Res. 40:439-452.

Sugden, M. C., P. W. Caton, and M. J. Holness. 2010. PPAR control: It's SIRTainly as easy as PGC. J. Endocrinol. 204:93-104.

Thering, B. J., M. Bionaz, and J. J. Loor. 2009. Long-chain fatty acid effects on peroxisome proliferator-activated receptor-alpharegulated genes in Madin-Darby bovine kidney cells: Optimization of culture conditions using palmitate. J. Dairy Sci. 92:2027-2037.

Vallim, T., and A. M. Salter. 2010. Regulation of hepatic gene expression by saturated fatty acids. Prostaglandins Leukot. Essent. Fatty Acids 82:211-218.

Velez, J. C., and S. S. Donkin. 2005. Feed restriction induces pyruvate carboxylase but not phosphoenolpyruvate carboxykinase in dairy cows. J. Dairy Sci. 88:2938-2948.

Yang, Y., A. R. Gocke, A. Lovett-Racke, P. D. Drew, and M. K. Racke. 2008. PPAR alpha regulation of the immune response and autoimmune encephalomyelitis. PPAR Res. 2008:546753.doi:10.1155/2 $008 / 546753$ 